\title{
Critical Success and Failure Factors of Entrepreneurial Organizations: Study of SMEs in Bahawalpur
}

\author{
Syed Wajahat Hussain Naqvi (Corresponding Author) \\ MBA-BBA Marketing \\ Dept. of Management Sciences, The Islamia University of Bahawalpur \\ Email: syedwajeh@gmail.com
}

Received: July 17, 2011 Accepted: August 01, 2011 DOI: 10.5296/jpag.v1i2.824

\begin{abstract}
Purpose of this research paper is to highlight those critical failure and success factors in SMEs of Bahawalpur. Models were developed from different studies. Finally results are generalized to SMEs of Bahawalpur. Findings suggest that customer service, know-how of the business and the past experience of the manager are the main key factors of success. Whereas different failure factors are explored out in which most crucial ones considered are lack of access to financial capital, inappropriate government structure and poor infrastructure as well as corruption. This paper has the vast implications for the SMEs in Pakistan and SMEs in Bahawalpur as it give insight into the reasoning factors of failure and success. Thus helps to identify failure and give guidance to success. Research is limited to small scale due to time constraint and resistive behavior of organizations.
\end{abstract}

Keywords: SME, Entrepreneurship, Failure Factors, Success Factors, Organization Success 


\section{Introduction}

Entrepreneurship is becoming of vital importance in the economies like Pakistan. Entrepreneurship is strongly related to small medium enterprise (SME), which is considered to be the main developing force of the developing economies market.

Previously many economists believed that it is the large firm which contributes in the developing of economies and attracts foreign exchange in the country. But there point of view changed when countries like Taiwan, Japan, and Korea established there economies of the bases of SMEs. These economies build up from grass root level to the heights of success.

According to Schapper (2006), in developing nations more than $90 \%$ of the firms fall under the category of SME and he also above than $90 \%$ of these firms are microenterprises. Pakistan is also one of the countries focusing on the development of SMEs. Almost 13 years ago Govt. of Pakistan established institution named SMEDA; small and medium enterprise authority, responsible for the guidance and the promotion of SMEs.

SMEs are very heterogeneous business operating in many different sectors such as trade, agri- business, manufacturing (Hussain etal, 2009). Pakistan is a very potential market for SMEs. Before very less or no importance is given on the business research which could attract many foreign investments. There are certain issues regarding the success and failures of SMEs which need to explore out and address.

This paper tries to understand and explore out the factors that contribute to the success and failure of any SMEs situated in Bahawalpur, the $12^{\text {th }}$ largest city of Pakistan situated in the Southern Punjab. Model from the different studies is formed and tested with the help of different studies and results are generalized. Due to a time constraint and different organization's resistive behavior, study is done on small scale.

\section{Literature Review}

SMEs are the backbone of many developing countries. SMEs contribute to the development economy in several ways; generating employment and providing services. According to the Economic Survey of Pakistan (2008-09) (Government of Pakistan - Ministry of Finance, 2009) SMEs are growing faster, contributed almost $99.06 \%$ in $2008-200$, responsible for the $30 \%$ of GDP. In Pakistan company is considered SME when it has employees up to 250, paid up capital of Rs. 25 million and annual sales of Rs. 250 million (SME Policy, 2007). Despite of its entire growth still SMEs are not giving their maximum and the rate of failure is very high (Hussain et al., 2010). Most of the SMEs in Pakistan are in low growth trap and in fact 19\% of the SMEs are less than 5 years old and only 4\% survive beyond 25 years (Khawaja, 2006). It becomes important to identify those factors that critically contribute to the success and failure of any SME.

In the context of Pakistan very few studies have been done. Before discussing about success, it must be defined first. There is no single-accepted definition of business success (Stefanovic et al., 2010). According to Jenning and Beaver (1997) it is very difficult to identify Success or Failure of a SME. Stefanovic et al. (2010) and Lussier and Pfiefer (2001) in simplest way 
define success as the company's ability to survive. Benzing et al., (2005), Chu et al., (2007), Coy et al.,( 2007), Duschesneau and Gartner (1990), Pratt (2001) stated that Owner's previous experience, interpersonal skills, access to capital, hard work are important drivers serve as the success of any organization. Experience and knowledge of the local market also plays a great role in the success (Hussain and Windsperger, 2010). A very excellent study in the context of success factors is done by Benzing and colleagues (2009) they categorized the factors contributing to the success of small businesses into three groups i.e. psychological and personal skills, management skills and training, and external environment. Stefanovic et al., (2010) Frese et al., (2002) describe urge of independence, innovativeness, attitude towards risk and a competitive nature as a psychological attributes relating to success. Managerial skills comprise of ability to manage work force and managing accounts, environmental conditions consists of sufficient governmental support, access to the capital and support of family and friends (Benzing et al., 2009).

Failure factors are often neglected. They really need to be explored out and addressed. Bezing et al,. (2009) states that unstable political and economic environment, complex taxation, corruption, and poor law and order situation are common problems faced by the developing countries. Report by Asian Development Bank (ADB) (2005) argues that there are certain factors that are constraint to the growth of SMEs such as credit rationing, high cost of credit and lease financing, high compliance cost, poor infrastructure, poor skill and training, market transaction cost, judicial constraints. According to Hussain et al.,( 2010) lack of financial assistance and unable to access capital are most critical environmental failure factors. In Pakistan SMEs show great dissatisfaction form the support of government and its institutions and also believe that increasing corruption in the country have put hurdles in doing business (Yaqub et al., 2010)

Above studies provide the ground for this research. Pakistan is facing lots of challenges. It is of very crucial to go far beyond the traditional doing of business.

\section{Research Objectives}

- To explore out critical factors influencing success of SMEs

- To explore out critical factors causing failure of SMEs

- To identify the most affecting factor regarding success and failure of SMEs

\section{Methodology}

This study aims to explore out factors that contribute to the success and failure of SMEs. Models are developed based on the study of Bezing et al. (2009), and ADB (2005). Due to the limitations like time constraint and resistive behavior of organizations study is done on small scale. Findings are generalized on SMEs of Bahawalpur. There are 600 SMEs listed in Bahawalpur Chamber of Commerce in which we evaluate SMEs in Bahawalpur City. 


\subsection{MODELS}
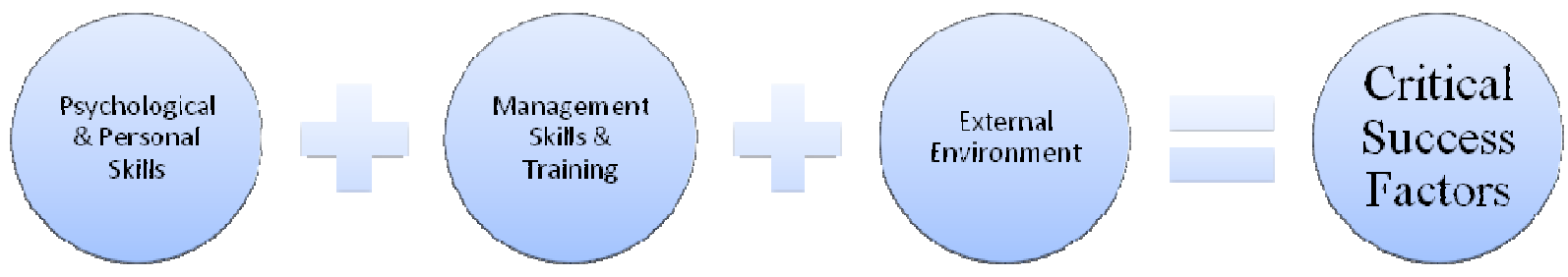

\section{Critical Failure Factors}
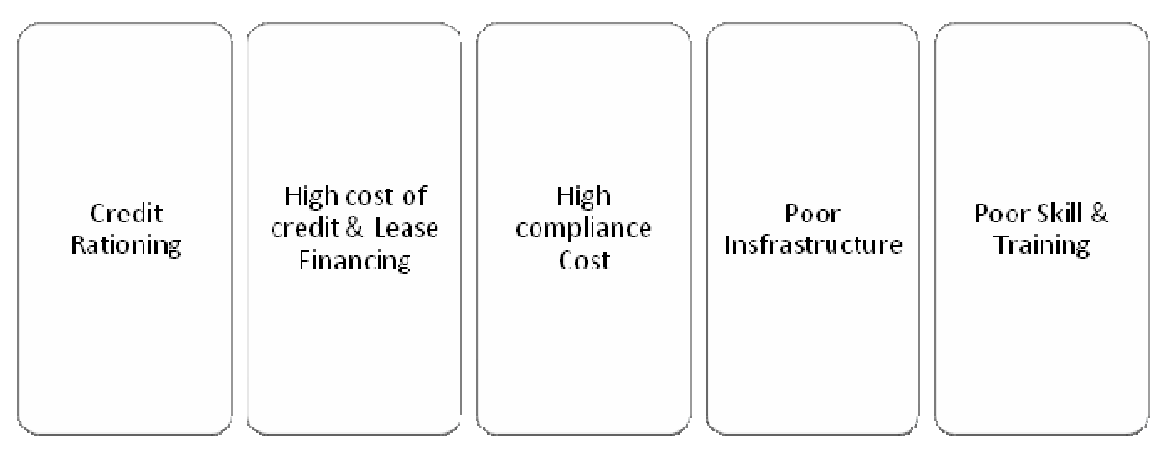

(a) (Adapted from Bezing et al., 2009)

\section{Findings and Discussion}

According to the model adapted from ADB (2005) there are certain factors that are constraints in the growth of SMEs in Pakistan. Credit rationing is a constraint on both supply and demand side, supply side arises because of the unawareness of the creditor's right and less popularity of SMEs. Whereas demand side arises due to the lengthy time consuming loan disbursements and lack of easy access to the capital. High cost of credit and lease finance is due to the high risk fee returns and small size of the lease companies. High compliance cost due to the direct contact between officials and firms entailing nontransparent rules and arising issue of corruption. Poor infrastructure is a very important factor in the failure of SMEs. It is Poor quality of service, lack of reliability and corruption in obtaining supplies. Poor training, skills, and lack of technical and business education raise the cost of firm growth. Proper education gives insight into many issues. Educational design in Pakistan is ill managed, poorly designed, distributed in public and private sector dilemma. Market transaction costs are high because of improper network between high quality intermediate goods and raw material suppliers, raising the issue of trust. Finally the Judicial constraint is of high and lengthy judicial procedures a great hurdle to enforce transparent procedures. Poor structure of judiciary gives strength to corruption and other illegal activities and constraining growth. We 
generalize these findings on the SMEs of Bahawalpur as it is the part of this system. Also in a study, done by Hussain et al., (2010) reveals that in Azad Jammu and Kashmir lack of financial assistance and unable to access capital are most critical environmental failure factors. In order to grow failure factors must be addressed in SMEs. (ADB, 2005; Yaqub et al., 2010)

Results of different studies on critical success factors of SMEs in Pakistan reveal that customer service is considered to be the most important factor (Yaqub et al., 2010; Bezing et al., 2005; Coy et al., 2007). Yaqub et al., (2010) also stated that entrepreneur's experience and specific know-how of the business sector are also important drivers of success.

\section{Conclusion}

SMEs are the backbone of any economy. This exploratory study aims to identify certain factors critical to the success and failure of the SMEs in Bahawalpur. Models are developed from the different studies and finally results are generalized on SMEs of Bahawalpur. Model testing revealed that customer service, know-how of the business and the past experience of the manager are the main key factors of success. Whereas different failure factors are explored out in which most crucial ones considered are lack of access to financial capital, inappropriate government structure and poor infrastructure as well as corruption.

Due to high failure of SMEs in Pakistan, this study tries to address the reasoning factors and as this study explores out different success factors, thus can be helpful for many SMEs in Pakistan as well as for SMEs in Bahawalpur, to identify the root cause and how to address them.

The future research may verify and extend this study by conducting on the large scale and using quantitative analysis.

\section{References}

- Asian Development Bank. (2005). SME Devlopment in Pakistan; Analyzing the constraint to growth.

- Benzing, C., Chu, M., and Callanan, G. (2005). Regional comparison of the motivation and problems of Vietnamese entrepreneurs. Journal of Developmental Entrepreneurship, 3, 3-27.

- Benzing, C., and Chu, M. (2005). Entrepreneurial behavior in Andhra Pradesh, India. Paper presented at the Annual Meeting of the Association for Global Business, Miami: FL, USA, November 8.

- Benzing, C., Chu., H. M., and Kara, O. (2009). Entrepreneurs in Turkey: A factor analysis of motivations, success factors, and problems. Journal of Small Business Management, 47(1), 58-91.

- Coy, S. P., Shipley, M. F., Omer, K., and Rao, N. A. (2007). Factors contributory to success: A study of Pakistan's small business owners. Journal of Developmental Entrepreneurship, 12(2), 189-198. 
- Chu, H. M., Benzing, C., and McGee, C. (2007). Ghanaian and Kenyan entrepreneurs: Analysis of their motivations, success characteristics and problem. Journal of Developmental Entrepreneurship, 6, 17-31.

- Duschesneau, D., and Gartner, W. (1990). A profile of new venture success and failure in an emerging industry. Journal of Business Venturing, 5, 197-312.

- Frese, M., Brantjes, A. and Hoorn, R. (2002) Psychological Success Factors of Small Scale Businesses in Namibia: The Roles of Strategy Process, Entrepreneurial Orientation and the Environment. Journal of Developmental Entrepreneurship, Vol. 7, No. 3, pp. 259-282.

- Hussain, D., and Windsperger, J. (2010). Multi-unit ownership strategy in franchising: Development of an integrated model. Journal of Marketing Channels, 17(1). 3-31.

- Hussain, I., Hussain, M. Hussain, S. and Si, S. (2009). Public Private partnership and SMEs Development; The case of AJ\&K Pakistan. International Review of Business Research paper, 5, 37-46.

- Hussain, I., Si, S., Xie, X.M. (2010). Comparative Study on Impact of Internal and External CFFs on SMEs. Journal of Small Business and Entrepreneurship 23, no. 4 (2010): pp. 637-648

- Jenning, P., and Beaver, G. (1997). The performance and competitive advantage of small firms: A management perspective. International Small Business Journal, 24(2), 63-76.

- Khawaja, S. 2006. Unleashing the Potential of the SME Sector with a Focus on Productivity Improvements [online].

- Lussier, R., and Pfeifer, S. (2001). A cross-national prediction model for business success. Journal of Small Business Management, 39(3), 228-237.

- Pratt, V. (2001). Sharing business skills in Kenya. Center for International Private Enterprise, Washington DC, www.cipe.org (retrieved on 29-05-2009)

- Schaper, M. T. (2006). Distribution pattern of small firms in developed economies: Is there an emergent global pattern? International journal of Entrepreneurship and Small Business, 3(2), 183-189.

- Stefanovic, I., Prokic, S., Rankovic, L. (2010). Motivational and success factors of entrepreneurs: the evidence from a developing country. Zb. rad. Ekon. fak. Rij. • 2010 -vol. $28 \cdot$ sv. $2 \cdot 251-269$.

- Yaqub, M. Z, and Hussain, D. (2010). Micro-enterpreneurs: Motivations Challenges and Success Factors. International Research Journal of Finance and Economics. 